\title{
Health-related quality of life and psychological distress in implantable cardioverter defibrillator patients with and without heart failure
}

\author{
Wong MF Florence \\ School of Nursing \\ Tung Wah College \\ Hong Kong \\ florencewong@twc.edu.hk
}

\begin{abstract}
Heart failure (HF) is one of the major health concerns worldwide due to high incidence and mortality. HF patients experience high level of psychological distress, particularly anxiety and depression. To increase survival rate, implantable cardioverter defibrillator (ICD) acts as a life-savor to deliver immediate shock to correct life-threatening arrhythmias as HF patients are the high-risk population for sudden cardiac arrest. It was attributed to unpredictable ICD shock. Moreover, some studies reported that ICD can improve health-related quality of life (HRQoL) among HF patients. However, ICD was evidenced to increase anxiety and depression. Psychological distress can also impair HRQoL of ICD patients. Due to different health conditions and health needs, ICD patients with and without HF can perceive different degrees of heightened psychological distress and declined HRQoL. Although the number of HF patients receiving ICD implantation has been increasing, inadequate knowledge is reported about their psychological status and HRQoL. To improve current ICD care to patients with and without HF, this study aimed to compare psychological status (anxiety and depression) and HRQoL and identify the relationships of personal and clinical characteristics with psychological status and HRQoL between ICD patients with and without HF. A total of 139 ICD patients were recruited, including 68 patients with HF. Those with HF perceived relatively higher depression and poorer physical HRQoL. Patients without HF who were married perceived better physical and mental health. Patients with HF who were more dependent have heightened anxiety and depression. The results shed light on the differences from the level of anxiety and depression among ICD patients with and without HF as well as their HRQoL so that ICD care for these two specific ICD patient groups can be directed. Family involvement is more significant for patients with and without HF.
\end{abstract}

Keywords- Implantable cardioverter defibrillator, heart failure, psychological distress, health-related quality of life

\section{INTRODUCTION}

Heart failure (HF) is one of the major cardiac problems with higher rates of incidence and mortality from sudden cardiac death (SCD) worldwide [1-3]. In the US, an estimated projection of $\mathrm{HF}$ cases was increased by $46 \%$ from 2012 to 2030 [2]. About $50 \%$ of HF patients will die within five years of diagnosis [4]. To increase survival rate, implantable cardioverter defibrillator (ICD) has been a favourable medical treatment to reduce mortality by delivering immediate ICD shock to restore normal heart rhythms [5,6]. Currently, an ICD

DOI: $10.5176 / 2345-71984.1 .122$

CThe Author(s) 2019. This article is published with open access by the GSTF device, called cardiac resynchronization therapy defibrillator (CRT-D), can provide two specific functions, anti-tachycardia pacing (ATP) and cardiac resynchronization therapy (CRT). ATP aims to reduce inappropriate shocks and CRT helps stimulate both ventricles to contract simultaneously to improve cardiac performance [7-9]. Therefore, the demand of $\mathrm{HF}$ patients receiving ICD has been increasing. As current health care emphasizes much on optimal health-related quality of life (HRQoL) that is beneficial to reduce demand of medical cost in treatment and rehabilitation, to prolong survival, and to shorten the hospitalization period [2,3], studies have been examining HRQoL in ICD patients. However, contradictory results were reported. Some studies reported that ICD patients perceived poorer HRQoL, particularly in physical aspects due to the possibility of ICD shock occurrence [10-13]. Studies were also conducted to examine HRQoL in patients with HF. Physical function was commonly affected in those patients $[10,11]$. Since HF patients are commonly reported to have poorer HRQoL, particularly physical health, due to insufficient cardiac function, ICD patients with HF will have double-folded physical restriction and disability due to inadequate cardiac function [10,14-15]. Eventually, those patients cannot maintain their daily activities of living and their ability of self-care declines [10,14]. However, knowledge about the effects of ICD on HRQoL among HF patients is still insufficient and inconsistent. Knackstedt and colleagues [16] reported that patients receiving ICD with or without CRT had no differences on HRQoL.

Anxiety and depression are commonly found in both HF patients $[17,18]$ and ICD patients $[14,19]$. These two emotions can poorly affect the patient's health condition [12,13,20-22] and are closely linked to higher mortality in cardiac patients $[23,24]$. Anxiety and, particularly, depression are important markers for cardiac diseases and high mortality [24,25]. Despite its main function in mortality reduction, ICDs were reported to bring heightened psychological distress to patients [26-28]. The past studies reported that about $24-33 \%$ of ICD patients perceived high level of depression and estimated 9$15 \%$ of them had clinically significant depression $[29,30]$. Since HF patients receiving ICD have been numbering, their anxiety and depression and associated factors can be different from those of patients without HF.

To provide appropriate care for ICD patients with or without HF having different health needs, the study aimed to 1) 
to compare psychological distress (anxiety and depression) and HRQoL between ICD patients with and without HF and 2) to identify relationships of demographic and clinical characteristics with psychological status and HRQoL. The results are useful to direct ICD care for improving HRQoL and reducing anxiety and depression with consideration of demographic and clinical factors between these two ICD specific groups.

\section{METHODS}

A secondary analysis was performed to further understand factors associated with psychological distress (anxiety and depression) and HRQoL of ICD patients with and without HF to understand better the direction to develop special care for ICD patients with and without HF.

\section{A. Design and sampling}

A cross-sectional questionnaire survey was conducted using convenience sampling. Patients were recruited at two hospitals when they 1$)$ were Chinese adults ( $\geq 18$ years old); 2 ) were ICD recipients with $\mathrm{HF} ; 3$ ) were able to communicate in Chinese; and 4) had no cognitive problems

\section{B. Data collection}

All eligible subjects were requested to sign an informed consent and then fill in one set of questionnaires, including the demographic and clinical form, the Chinese-Cantonese version of the Hospital Anxiety and Depression Scale (HADS) and the Chinese (Hong Kong) version of the Medical Outcomes Study 36-Item Short-Form Health Survey (SF-36v2) via face-to-face interview. ICD data were obtained from medical records of patients. The interview took about 20 minutes.

The SF-36v2 was also widely used to measure HRQoL outcomes. It consists of eight subscales and two component summary scores. The higher scores the better perceived HRQoL level [31]. The Cronbach's alphas of the eight domains of SF-36v2 ranged from 0.78 to 0.98 in this study.

The HADS is a widely used tool for depression and anxiety. It consists of 7 items for depression and 7 items for anxiety using 4-point Likert scale ranging from 0 (absence of symptoms) to 3 (severe symptoms). The total scores for each subscale range from 0 to 21 and the overall score ranges from 0 to 42. A cut-off score of $\geq 8$ for each subscale indicates clinically significant levels of depression and anxiety [32]. The HAD-A, HAD-D, and overall HADS indicated good reliability with the Cronbach's alphas $0.75,0.76$, and 0.83 , respectively.

\section{ETHICAL CONSIDERATIONS}

Ethical approval was sought by the School Research Committee of the educational institution. All subjects were assured that they could withdraw from the study without consequences at any time. All information was anonymous for personal confidentiality.

\section{DATA ANALYSIS}

Data were analyzed using the IBM SPSS v20.0 0 (IBM Corporation, Armonk, New York, USA). Descriptive statistics were performed to summarize independent variables (patients' demographics, HADS subscales, anxiety and depression) for
ICD patients with and without HF. Univariate analyses were used to assess the relationships between independent variables and, depression level and anxiety level using Pearson's correlation coefficient, independent-samples t-test, or one-way ANOVA between two ICD patient groups. All statistical tests involved were two-sided. The type I error rate (level of significance) was set at 0.05 .

\section{RESULTS}

A total of 139 ICD patients were recruited, including 68 patients with $\mathrm{HF}(\sim 50 \%)$.

\section{A. Demographic charcteristics}

Their mean age was $64.24 \pm 12.35$ years old. There were 53 males $(\sim 78 \%)$ and $52(76.5 \%)$ married and living with family. Most of the ICD patients with HF $(n=64 ; 94.1 \%)$ were selfcare independent.

About $30-40 \%$ of ICD patients with HF had comorbidities such as coronary artery disease (CAD), hypertension (HT), atrial fibrillation (AF), and diabetes mellitus (DM). Compared to ICD patients without HF, those with HF had relatively more comorbidities.

Regarding ICD-related characteristics, $64.7 \%$ of ICD patients with HF received CRT-D. However, 5 ICD patients without HF (7\%) had ICD shock experience and $3(4.2 \%)$ had more than one ICD shock experience. This was a higher rate as compared to those with HF.

Table I shows the details of demographic and clinical characteristics of the ICD patients with and without HF.

TABLE I. DEMOGRAPHIC AND CLINICAL CHARACTERISTICS

\begin{tabular}{|c|c|c|}
\hline \multirow{2}{*}{ Demographic characteristics } & ICD only $(n=71)$ & ICD with $H F(n=68)$ \\
\hline & $\operatorname{Mean}(S D) / n(\%)$ & Mean (SD)/n (\%) \\
\hline Age (years) ${ }^{\psi}$ & $59.01(15.47)$ & $64.24(12.35)$ \\
\hline$\geq 60$ years old & $43(60.5)$ & $54(79.40)$ \\
\hline Male & $54(76.1)$ & $53(77.9)$ \\
\hline Married / cohabiting & $55(77.5)$ & $52(76.5)$ \\
\hline Self-care independence & $67(94.4)$ & $64(94.1)$ \\
\hline \multicolumn{3}{|l|}{ Educational level } \\
\hline Primary or below & $27(38.0)$ & $30(44.1)$ \\
\hline Secondary or above & $44(62.0)$ & $16(45.7)$ \\
\hline Retired / unemployed & $45(63.4)$ & $58(85.3)$ \\
\hline \multicolumn{3}{|l|}{ Clinical characteristics } \\
\hline Hypertension (HT) & $18(25.4)$ & $27(39.7)$ \\
\hline Hyperlipidemia & $6(12.8)$ & $26(38.2)$ \\
\hline Ischemic heart disease (IHD) & $24(33.8)$ & $33(48.5)$ \\
\hline Atrial fibrillation (AF) & $13(18.3)$ & $21(30.9)$ \\
\hline Diabetes mellitus (DM) & $12(16.9)$ & $25(36.8)$ \\
\hline $\begin{array}{l}\text { Chronic obstructive airway } \\
\text { disease (COAD) }\end{array}$ & $3(4.2)$ & $6(8.8)$ \\
\hline \multicolumn{3}{|l|}{ ICD-related characteristics } \\
\hline CRT-D & $6(8.5)$ & $44(64.7)$ \\
\hline Implantation period (years) ${ }^{\psi}$ & $3.79(1.37)$ & $3.51(1.31)$ \\
\hline $\begin{array}{l}\text { Implantation period }>12 \\
\text { month }\end{array}$ & $58(81.7)$ & $52(76.5)$ \\
\hline First timer of implantation & $54(76.1)$ & $56(82.4)$ \\
\hline With ICD shock experience & $5(7.0)$ & $3(4.4)$ \\
\hline \multicolumn{3}{|l|}{ Frequency of ICD shock } \\
\hline Once & $2(2.8)$ & $2(2.9)$ \\
\hline$\geq$ Twice & $3(4.2)$ & $1(1.5)$ \\
\hline
\end{tabular}


Data marked with ${ }^{\psi}$ are presented as mean (standard deviation), whereas the others are presented as frequency $(\%)$.

\section{B. HRQoL between ICD patients with and without heart failure (Table 2)}

Based on the subscales of SF-36v2, the scores of physical functioning (PF) and vitality (VIT) were found to have relative large differences between ICD patients with and without HF (PF: mean $67.57 \pm 28.20$ vs mean $75.07 \pm 24.92$, respectively; VIT: mean $48.44 \pm 29.56$ vs mean $60.56 \pm 28.16$, respectively). Moreover, the PCS score was lower in ICD patients with HF compared to those without HF (mean $37.84 \pm 14.94$ vs mean $41.36 \pm 13.92$, respectively).

TABLE II. HEALTH-RELATED QUALITY OF LIFE BETWEEN ICD PATIENTS WITH AND WITHOUT HEART FAILURE

\begin{tabular}{|l|c|c|}
\hline \multirow{2}{*}{$\begin{array}{l}\text { Health-related quality of life } \\
\text { [SF-36v2] }\end{array}$} & $\frac{\text { ICD without HF }}{(n=71)}$ & $\frac{I C D \text { with } H F}{(n=68)}$ \\
\cline { 2 - 3 } & Mean $(S D) / n(\%)$ & Mean $(S D) / n(\%)$ \\
\hline Physical functioning subscale & $75.07(24.92)$ & $67.57(28.20)$ \\
\hline Role physical subscale & $71.57(37.47)$ & $67.28(35.60)$ \\
\hline Bodily pain subscale & $83.46(23.91)$ & $86.51(23.42)$ \\
\hline General health subscale & $50.65(28.56)$ & $49.54(24.62)$ \\
\hline Vitality subscale & $60.56(28.16)$ & $48.44(29.56)$ \\
\hline Social functioning subscale & $89.96(23.11)$ & $89.34(22.47)$ \\
\hline Role emotional subscale & $88.62(22.72)$ & $91.67(21.79)$ \\
\hline Mental health subscale & $76.48(22.05)$ & $78.09(20.75)$ \\
\hline $\begin{array}{l}\text { Physical component summary } \\
\text { (PCS) }\end{array}$ & $41.36(13.92)$ & $37.84(14.94)$ \\
\hline $\begin{array}{l}\text { Mental component summary } \\
\text { (MCS) }\end{array}$ & $55.76(10.93)$ & $55.96(9.92)$ \\
\hline
\end{tabular}

Data marked with ${ }^{\psi}$ are presented as mean (standard deviation), whereas the others are presented as frequency $(\%)$.

\section{Psychological status between ICD patients with and without heart failure (Table 3 )}

Among the 68 ICD patients with HF, $11.80 \%$ of them $(n=8)$ had significant levels of anxiety (HADS-A $\geq 8)$ and $22.1 \%$ of them $(n=15)$ reported significant levels of depression (HADS-D $\geq 8$ ). The mean scores of HADS-D and HADS-A were $4.15(\mathrm{SD}=3.78)$ and $3.26(\mathrm{SD}=3.74)$ respectively.

Among the 71 ICD patients without HF, $16.90 \%$ of them $(n=12)$ had significant levels of anxiety and $18.3 \%$ of them $(n=13)$ reported significant levels of depression. The mean scores of HADS-D and HADS-A were 4.23 ( $\mathrm{SD}=4.08)$ and $3.59(\mathrm{SD}=3.52)$, respectively.

TABLE III. PSYCHOLOGICAL STATUS BETWEEN ICD PATIENTS WITH AND WITHOUT HEART FAILURE

\begin{tabular}{|c|c|c|}
\hline & $\frac{\text { ICD without } H F}{(n=71)}$ & $\underline{I C D}$ with $H F(n=68)$ \\
\hline & $\operatorname{Mean}(S D) / n(\%)$ & $\operatorname{Mean}(S D) / n(\%)$ \\
\hline $\begin{array}{l}\text { HADS-Depression: } \\
(\text { Score } \geq 8)\end{array}$ & $13(18.3)$ & $15(22.1)$ \\
\hline $\begin{array}{l}\text { HAD-Anxiety: } \\
(\text { Score } \geq 8)\end{array}$ & $12(16.9)$ & $8(11.8)$ \\
\hline HADS-Depression ${ }^{\psi}$ & $4.23(4.08)$ & $4.15(3.78)$ \\
\hline HADS-Anxiety ${ }^{\psi}$ & $3.59(3.52)$ & $3.26(3.74)$ \\
\hline HADS overall $^{\psi}$ & $7.82(6.65)$ & $7.41(6.72)$ \\
\hline
\end{tabular}

Data marked with ${ }^{\psi}$ are presented as mean (standard deviation)

Relationships of HRQoL with demographic and clinical characteristics between ICD patients with and without HF (Table 4)

The results showed that education $(\gamma=0.39, \mathrm{p}=0.001)$, being married $(\gamma=0.25, p=0.033)$, self-care independence $(\gamma=0.32, p=0.007)$, and occupation $(\gamma=0.33, p=0.005)$ had positive relationships, while old age $(\geq 60$ years old $)(\gamma=-0.31$, $\mathrm{p}=0.008)$, having AF $(\gamma=-0.32, \mathrm{p}=0.007)$, and receiving CRT$\mathrm{D}(\gamma=-0.25, \mathrm{p}=0.040)$ had negative relationships with PCS among ICD patients without HF. Whereas being married $(\gamma=$ $0.34, p=0.004)$ and having IHD $(\gamma=0.30, p=0.011)$ had negative correlations with MCS among ICD patients without HF.

Among ICD patients with HF, education $(\gamma=0.33$, $\mathrm{p}=0.007)$, occupation $(\gamma=0.33, \mathrm{p}=0.006)$, and self-care independence $(\gamma=0.36, \mathrm{p}=0.002)$ had positive relationships, but old age $(\geq 60$ years old $)(\gamma=-0.34, p=0.004)$ and having DM $(\gamma=-0.34, p=0.005)$ had negative correlations with PCS. However, there were no variables correlated with MCS.

TABLE IV. RELATIONSHIPS OF HRQOL AND PSYCHOLOGICAL DISTRESS (ANXIETY AND DEPRESSION) BETWEEN ICD PATIENTS WITH AND WITHOUT HF

\begin{tabular}{|c|c|c|c|c|}
\hline & \multicolumn{2}{|c|}{ PCS } & \multicolumn{2}{|c|}{ MCS } \\
\hline & $\begin{array}{c}\text { Pearson } \\
\text { correlation }\end{array}$ & $\mathrm{p}$ & $\begin{array}{c}\text { Pearson } \\
\text { correlation }\end{array}$ & $\mathrm{p}$ \\
\hline \multicolumn{5}{|c|}{ ICD without HF $(n=71)$} \\
\hline$\geq 60$ years old & -0.31 & 0.008 & & \\
\hline Education & 0.39 & 0.001 & & \\
\hline Being married & 0.25 & 0.033 & 0.34 & 0.004 \\
\hline $\begin{array}{l}\text { Self-care } \\
\text { independence }\end{array}$ & 0.32 & 0.007 & & \\
\hline Occupation & 0.33 & 0.005 & & \\
\hline Having IHD & & & 0.30 & 0.011 \\
\hline Having AF & -0.32 & 0.007 & & \\
\hline $\begin{array}{l}\text { Receiving } \\
\text { CRT-D }\end{array}$ & -0.25 & 0.040 & & \\
\hline \multicolumn{5}{|c|}{ ICD with HF (n=68) } \\
\hline & $\begin{array}{c}\text { Pearson } \\
\text { correlation }\end{array}$ & $\mathrm{p}$ & $\begin{array}{l}\text { Pearson } \\
\text { correlation }\end{array}$ & $\mathrm{p}$ \\
\hline$\geq 60$ years old & -0.34 & 0.004 & & \\
\hline Education & 0.33 & 0.007 & & \\
\hline $\begin{array}{l}\text { Self-care } \\
\text { independence }\end{array}$ & 0.36 & 0.002 & & \\
\hline Occupation & 0.33 & 0.006 & & \\
\hline Having DM & -0.34 & 0.005 & & \\
\hline
\end{tabular}

D. Relationships of psychological stress (anxiety and depression) with demographic and clinical characteristics between ICD patients with and without HF (Table 5)

The results showed that old age ( $\geq 60$ years old $)(\gamma=0.27$, $\mathrm{p}=0.022)$, having $\operatorname{COAD}(\gamma=0.28, \mathrm{p}=0.017)$, and receiving CRT-D $(\gamma=0.33, p=0.004)$ had positive relationships, but being married $(\gamma=-0.30, p=0.013)$, education $(\gamma=-0.28$, $\mathrm{p}=0.019)$, and occupation $(\gamma=0.24, \mathrm{p}=0.046)$ had negative relationships with depression among ICD patients without HF. 
Whereas only having IHD $(\gamma=-0.28, p=0.017)$ had negative correlation with anxiety among ICD patients without HF.

Among ICD patients with HF, old age ( $\geq 60$ years old) $(\gamma=0.24, p=0.046)$ and having DM $(\gamma=0.30, p=0.012)$ had positive correlations, but education $(\gamma=-0.25, \mathrm{p}=0.040)$ and self-care independence $(\gamma=-0.31, p=0.011)$ had negative correlations with depression. Whereas self-care independence $(\gamma=-0.27, p=0.027)$ had negative correlation with anxiety.

TABLE V. RELATIONSHIPS OF PSYCHOLOGICAL DISTRESS (ANXIETY AND DEPRESSION) BETWEEN ICD PATIENTS WITH AND WITHOUT HF

\begin{tabular}{|c|c|c|c|c|}
\hline & \multicolumn{2}{|c|}{ Anxiety } & \multicolumn{2}{|c|}{ Depression } \\
\hline & $\begin{array}{c}\text { Pearson } \\
\text { correlation }\end{array}$ & $\mathrm{p}$ & $\begin{array}{c}\text { Pearson } \\
\text { correlation }\end{array}$ & $\mathrm{p}$ \\
\hline \multicolumn{5}{|c|}{ ICD without HF $(n=71)$} \\
\hline$\geq 60$ years old & & & 0.27 & 0.022 \\
\hline Education & & & -0.28 & 0.019 \\
\hline Being married & & & -0.30 & 0.013 \\
\hline Occupation & & & -0.24 & 0.046 \\
\hline IHD & -0.28 & 0.017 & & \\
\hline COAD & & & 0.28 & 0.017 \\
\hline $\begin{array}{l}\text { Receiving } \\
\text { CRT-D }\end{array}$ & & & 0.33 & 0.004 \\
\hline \multicolumn{5}{|c|}{ ICD with HF $(n=68)$} \\
\hline & $\begin{array}{c}\text { Pearson } \\
\text { correlation }\end{array}$ & $\mathrm{p}$ & $\begin{array}{c}\text { Pearson } \\
\text { correlation }\end{array}$ & $\mathrm{p}$ \\
\hline$\geq 60$ years old & & & 0.24 & 0.046 \\
\hline Education & & & -0.25 & 0.040 \\
\hline $\begin{array}{l}\text { Self-care } \\
\text { independence }\end{array}$ & -0.27 & 0.027 & -0.31 & 0.011 \\
\hline $\mathrm{DM}$ & & & 0.30 & 0.012 \\
\hline
\end{tabular}

\section{DISCUSSION}

This study results addressed the aims to understand the HRQoL and psychological status between ICD patients with and without HF as well as their relationships with patients' demographic and clinical characteristics. The results revealed that ICD patients with HF were relatively older than those without HF. It also explained why those with HF were more likely to have more comorbidities. Those patients had relatively poorer cardiac conditions and hence they were more likely to receive CRT-D to optimize their wellbeing for normal daily activities by improving overall cardiac performance [79].

Based on the results of HRQoL, ICD patients with HF had poorer physical health probably due to their poor cardiac conditions. Although most of the HF patients had received CRT-D, there was no data related to physical wellbeing before implantation to understand more about the effects of CRT-D on physical health. Nevertheless, the mental health was comparable between the two groups.

The levels of anxiety and depression were comparable between patients with HF and those without. However, a higher percentage of anxiety at clinically significant level (score $\geq 8$ ) yet a lower percentage of depression at clinically significant level (score $\geq 8$ ) were found in patients without $\mathrm{HF}$ than those with HF. The higher level of anxiety was found in those without HF most probably due to unpredictable ICD shocks and new adaptation to live with the device. Although ICD acts as a lifesaver, its shock is unpredictable and can induce physical pain $[26,33]$. Therefore, those who had experienced ICD shock would perceive more anxiety [34]. A higher frequency of ICD shock was found in patients without HF; hence, they might feel more anxious. Nevertheless, more patients with HF perceiving higher level of depression could be due to poor cardiac conditions $[13,22,27,40]$ and limited physical activity [35,36].

Moreover, diversities of demographic and clinical characteristics were found to be correlated with HRQoL (physical and mental) and psychological distress (anxiety and depression) between two ICD patient groups. It is important for healthcare professionals to pay close attention to specific ICD patients with different health needs, in particular those who have comorbidities, to reduce psychological distress and optimize both physical and mental HRQoL. Patients without HF who are of older age ( $\geq 60$ years old), undereducated, retired/unemployed, unmarried, more dependent, diagnosed with AF, or implanted with conventional ICD will be more likely to have poor physical health and ability. Old age may affect physical activity due to decreased muscle tone and limited physical tolerance $[37,38]$. Retirement or unemployment was found to affect physical health; it could be due to old age and altered general health conditions. Patients who are married will have more support and assistance from family, leading to better physical health. Patients with AF or received conventional ICD indicate poorer health conditions, leading to further deterioration of physical wellbeing [13]. AF lowers cardiac output, resulting in physical intolerance. Patients receiving conventional ICD have poorer physical health probably because they have to adapt to living with the device [39] and have to limit some physical activities to avoid inappropriate shocks. Moreover, patients without HF who are married and have a history of IHD will have better mental health. It can be explained by the fact that married patients can receive psychological support from their families. Patients with a history of IHD perceive better mental health probably due to their previous heart attack(s) and receiving ICD as a lifesaver. It is important to note that patients without HF who are married will have better physical and mental health most probably due to family involvement in their recovery.

Considering the physical health among ICD patients with HF, those who were older ( $\geq 60$ years old), undereducated, retired/unemployed, more dependent, and diagnosed with DM had poorer physical health [13]. Patients with HF who are of older age face further deterioration of physical health due to insufficient cardiac function. ICD patients with HF have poorer physical health most probably due to poorer cardiac function, leading to poorer physical ability and tolerance [22,40,41]. Those who need more assistance and dependence for daily activities have poorer physical ability $[41,42]$. Adequate support is crucial to ICD patients as they need to adapt to living with their device. ICD patients with HF need more support and assistance from their families as their poor cardiac function reduces their physical ability, implying that they require more dependence on others to maintain their daily activities $[41,43,44]$. Those with DM suffer from physical intolerance probably due to insufficient insulin to regulate blood glucose level [13]. However, there were no demographic and clinical characteristic found to be correlated with mental health among patients with HF. It is important to note that 
patients with HF will have more concerns about their physical health and ability.

Among ICD patients without HF, those who had a history of IHD perceived less anxiety. The reason may be that those patients have had previous experience of heart attack(s) and they have had more confidence in their ICD for protecting them from life-threatening episodes. More importantly, ICD patients without HF who are of older age ( $\geq 60$ years old), undereducated, unmarried, retired or unemployed, had a history of COAD, or received CRT-D perceive more depression. Patients who are of older age ( $\geq 60$ years old) are more likely to be retired. Older ICD patients without HF have more depression, perhaps due to their deteriorated general health [45-47], reduced physical ability, reduced ability for self-care, and role changes $[33,41,42,48,49]$. Due to their unfavorable cardiac condition, they may need to have early retirement. In addition, due to role changes after retirement and at older ages, patients feel more depressed to adapt to their new roles and living habits [41,50]. Patients without HF who have other illnesses, such as COAD, can face deteriorated physical health and ability, leading to more depression. COAD is a progressive respiratory disease that increases physical restriction and intolerance due to inadequate oxygenation. Receiving CRT-D can improve cardiac condition of patients but to patients without HF, receiving CRT-D induces higher risk of depression. Further investigation is needed.

Considering ICD patients with HF on anxiety and depression, those who are more self-care dependent will perceive more anxiety. Patients with HF may need to have more assistance from others. The increase in dependence may induce more negative emotions due to low self-esteem and poor body image. Moreover, patients with HF who are of older age ( $\geq 60$ years old), lower education level, are more self-care dependent, or are having DM perceive higher level of depression. ICD patients with HF who are more self-care dependent feel more depressed, which may be due to inadequate support [43]. Those with HF who have DM will be more depressed probably due to deterioration of general health condition. It is important to note that patients with HF having more self-care dependence will perceive more anxiety and depression.

This study has some limitations. A cross-sectional design might not be able to provide the causal inference and information about the changes in psychological status and HRQoL in different periods for comparisons between two groups. Previous studies reported that ICD shock could lower HRQoL and increase psychological distress [26,51]. However, only a few patients in the two groups had ICD shock experience. Further study with a larger sample can be performed to understand more about ICD shock in ICD patients with and without HF. Therefore, predictors of psychological distress and HRQoL can be identified in a larger sample.

\section{CONCLUSION}

Psychological distress and poor HRQoL are major health concerns particularly while caring for cardiac patients. Since ICD patients both with and without HF are numbering, they can have different degrees of heightened psychological distress and poorer HRQoL. As caring for HF patients with
ICD is a long-term endeavour, it is important for healthcare professionals to understand more about the differences of and possible factors correlated with psychological distress and HRQoL between ICD patients with and without HF. This study helps understand more about HRQoL and psychological distress as well as factors related to demographic and clinical characteristics between patient with and without ICD. Therefore, such results provide clear direction to develop and implement appropriate interventions targeting the possible factors to reduce psychological distress and improve HRQoL in ICD patients with different health needs, such as HF. Healthcare professionals can closely monitor the changes of psychological status and HRQoL by screening on a regular basis. Family involvement and adequate instructions may help improve patients' self-care ability and adaptation to the new lifestyle of living with the device [13]. Psychological intervention [52,53] and cognitive behavioural intervention with appropriate coping strategies and stress management [54,55] can be implemented to reduce psychological distress and maximize HRQoL.

\section{REFERENCES}

[1] W. Jiang, M. Kuchibhatia, M. S. Cuffe, E. J. Christopher, J. D. Alexander, G. L. Clary, M. A. Blazing, L. H. Gaulden, R. M. Califf, R. R. Krishnan, C. M. O'Connor. "Prognostic value of anxiety and depression in patients with chronic heart failure". Circulation, 110, 3452-3456, 2004.

[2] D. Mozaffarian, E. J. Benjamin, A. S. Go, D. K. Arnett, M. J. Blaha, M. C. Sandeep, S. de Ferranti, J. P. Després, H. J Fullerton, et al., "Heart disease and stroke statistics 2016 update: A report from the American Heart Association. Available from: http://circ.ahajournals.org/content/early/2015/12/16/CIR.0 000000000000350.

[3] J. E. Sanderson and T. F. Tse, "Heart failure: a global disease requiring a global response", Heart, 89, 585-586, 2003.

[4] Centre for Health Protection (CHP), "Number of deaths by leading causes of death, 2001-2015". Available from http://www.chp.gov.hk/en/data/4/10/27/380.html, 2016.

[5] G.H. Bardy., K.L Lee., D.B. Mark., J.E. Poole, D. L. Packer, R. Boineau, M. Domanski, et al., "Amiodarone or an implantable-defibrillator for congestive heart failure", $N$ Engl J Med, 352, 225-237, 2005.

[6] B. A. Koplan, "Ventricular Tachycardia and Sudden Cardiac Death", Mayo Clinic Proc, 84(3), 289-297, 2009.

[7] A. Kadish and M. Mehra, "Heart failure devices: implantable cardioverter-defibrillators and biventricular pacing therapy", Circulation, 111(24), 3327-3335, 2005.

[8] G. Paparella, L. Sciarra, L. Capulzini, A. Francesoni, C. De Asmundis, A. Sarkozy, R. Cazzin and P. Brugada, "Long-term effects of upgrading to biventricular pacing: differences with cardiac resynchronization therapy as primary indication", PACE, 33, 841-849, 2010.

[9] M. S. Wathen, P. J. DeGroot, M. O. Sweeney, A. J. Stark, M. F. Otterness, W. O. Adkisson, R. C. Canby, et al., "Prospective randomized multicenter trial of empirical antitachycardia pacing versus shocks for spontaneous rapid ventricular tachycardia in patients with implantable cardioverter-defibrillators: Pacing fast ventricular tachycardia reduces shock therapies (PainFREE Rx II) trial results", Circulation, 110(17), 2591-2596, 2004.

[10] R. Coelho, S. Ramos, J. Prata, P. Bettencourt, A. Ferreira, and M. Cerqueira-Gomes, "Heart failure and health related 
quality of life", Clin Pract Epidemiol Ment Health, doi:10.1186/1745-0179-1-19, 2005.

[11] F. Sawafta and X. Chen, "Quality of life of Chinese heart failure patients and their family caregivers", IJAST, 3(2), 77-88, 2013

[12] F. Wong, J. Sit, and E. Wong, "Factors influencing healthrelated quality of life (HRQOL) in patients with implantable cardioverter defibrillator (ICD): A systematic review", JBI Library of Systematic Review, 10(43), 27852881, 2012.

[13] F. M. F. Wong, J.W.H. Sit, E.M.L. Wong, and K.C. Choi, "Factors associated with health-related quality of life among patients with implantable cardioverter defibrillator: Identification of foci for nursing intervention", JAN, 70(12), 2821-2834, 2014.

[14] M. L. Chung, D. K. Moser, T. A. Lennie, and M. K. Rayens, "The effects of depressive symptoms and anxiety on quality of life in patients with heart failure and their spouses: testing dyadic dynamics using Actor-Partner Model", J Psychosom Res, 67, 29-35, 2008.

[15] J. Juenger, D. Schellberg, S. Kraemer, A. Haunstetter, C. Zugck, W. Herzog, and M. Haass, "Health related quality of life in patients with congestive heart failure: comparison with other chronic diseases and relation to functional variables", Heart, 87, 235-241, 2002.

[16] C. Knackstedt, M Arndt, K Mischke, N Marx, F Nieman, HJ Kunert, P Schauerte, C Norra, "Depression, psychological distress, and quality of life in patients with cardioverter defibrillator with or without cardiac resynchronization therapy", Heart Vessels, 29(3), 364$374,2014$.

[17] W. Jiang, J. Alexander, E. Christopher, M. Kuchibhatla, L. H. Gaulden, M.S. Cuffe, M.A. Blazing, et al., "Relationship of depression to increased risk of mortality and rehospitalization in patients with congestive heart failure", Arch Intern Med, 161, 1849-1856, 2001.

[18] V. Konstam, D. K. Moser, and M. J. De Jong, "Depression and anxiety in heart failure", $J$ Card Fail, 11(6), 455-463, 2015.

[19] J. B. Johansen, S. S. Pedersen, H. Spindler, K. Andersen, J. C. Nielsen, and P. T. Mortensen, "Symptomatic heart failure is the most important clinical correlate of impaired quality of life, anxiety, and depression in implantable cardioverter-defibrillator patients: a single-centre, crosssectional study in 610 patients", Europace, 10, 545-551, 2008.

[20] D. L. Hare, S. R. Toukhsati, P. Johansson, and T. Jaarsma, "Depression and cardiovascular disease: A clinical review", Eur Heart J, doi:10.1093/eurheartj/eht462, 2013.

[21] A. O'Neil, C. E. Stevenson, E. D. Williams, D. Mortimer, B. Oldenburg, \& K. Sanderson, "The health-related quality of life burden of co-morbid cardiovascular disease and major depressive disorder in Australia: findings from a population-based cross-sectional study", Qual Life Res, 22, 37-44, 2013.

[22] C. N. Hallas, J. L. Burke, D. G. White, and D. T. Connelly, "A prospective 1-year study of changes in neuropsychological functioning after implantable cardioverter-defibrillator surgery", Circ Arrhythm Electrophysiol, 3(2), 170-177, 2010.

[23] J. J. Strik, J. Denollet, R. Lousberg, and A. Honig, "Comparing symptoms of depression and anxiety as predictors of cardiac events and increased health care consumption after myocardial infarction", $J \mathrm{Am}$ Coll Cardiol, 42(10), 1801-1807, 2003.

[24] C. Welin, G. Lappas, and L. Wilhelmsen, "Independent importance of psychosocial factors for prognosis after myocardial infarction", J Intern Med, 247, 629-639, 2000.
[25] R. M. Carney and K. E. Freedland, "Depression, mortality, and medical morbidity in patients with coronary heart disease", Biol Psychiatry 54, 241-247, 2003.

[26] D. L. Carroll and G. A. Hamilton, "Quality of life in implanted cardioverter defibrillator recipients: The impact of a device shock", Heart Lung, 34(3), 169-178, 2005.

[27] S. F. Sears and J. B. Conti, "Quality of life and psychological functioning of ICD patients", Heart, 87(5), 488-493, 2002.

[28] S. A. Thomas, E. Friedmann, C. W. Kao, P. Inguito, M. Metcalf, F. J. Kelly, and S. S. Gottlieb, "Quality of life and psychological status of patients with implantable cardioverter defibrillators", Am J Crit Care, 15(4), 389398, 2006.

[29] R. Amiaz, E. Asher, G. Rozen, E. Czerniak, M. Glikson, and M. Weiser, "Do implantable cardioverter defibrillators contribute to new depression or anxiety symptoms? A retrospective study", Int J Psychiatry in Clin Pract, 20, 101-105, 2016.

[30] T. Shiga, T. Suzuki, K. Nishimura, "Psychological distress in patients with an implantable cardioverter defibrillator", JArrhythm, 29(6), 310-313, 2013.

[31] J. E. Ware, M. Kosinski, J. B. Bjorner, D. M. TurnerBowker, B. Gandek, and M. E. Maruish, "SF-36v2® Health Survey: Administration Guide for Clinical Trial Investigators". Lincoln, R. I: QualityMetric Incorporated, 2008.

[32] I. Bjeland, A. A. Dahl, T. T. Haug, and D. Neckelmann, "The validity of the Hospital Anxiety and Depression Scale An updated literature review", J Psychom Res, 52, 69-77, 2002.

[33] H. C. Kamphuis, J. R. de Leeuw, R. Derksen, R. N. Hauer and J. A. Winnubst, "Implantable cardioverter defibrillator recipients: quality of life in recipients with and without ICD shock delivery: a prospective study", Europace, 5(4), 381-389, 2003.

[34] M. E. Josephson and H. J. J. Wellens, "Implantable defibrillators and sudden cardiac death", Circulation, 109 , 2685-2691, 2004.

[35] V. Freedenberg, S. A. Thomas, and E. Friedmann, "Anxiety and depression in implanted cardioverterdefibrillator recipients and heart failure: a review", Heart Fail Clin, 7, 59-68, 2011.

[36] S. S. Pedersen, M. T. Hoogwegt, L. Jordaens, D. A. Theuns. "Relation of systematic heart failure and psychological status to persistent depression in patients with implantable cardioverter-defibrillator", Am. J. Cardiol. 1, 108(1), 69-74, 2011.

[37] G. A. Hamilton and D. L. Carroll, "The effects of age on quality of life in implantable cardioverter defibrillator recipients", JOCN, 13(2), 194-200, 2003

[38] S. F. Sears, T. S. Lewis, E. A. Kuhl, and J. B. Conti, "Predictors of quality of life in patients with implantable cardioverter defibrillators", Psychosomatics, 46 (5), 451457, 2005.

[39] F. Jacq, G. Foulldrin, A. Savouré, F. Anselme, A. Baguelin-Pinaud, A. Cribier, and F. Thibaut, "A comparison of anxiety, depression and quality of life between device shock and nonshock groups in implantable cardioverter defibrillator recipients", Gen Hosp Psychiatry, 31(3), 266-273, 2009.

[40] S. Kapa, D. Rotondi-Trevisan, Z. Mariano, T. Aves, J. Irvine, P. Dorian, and D. L. Hayes, "Psychopathology in patients with ICDs over time: Results of a prospective study", PACE, 33(2), 198-208, 2010.

[41] F. Wong, "Promoting health-related quality of life in patients with an implantable cardioverter defibrillator", Nursing Standard, 3I(27), 53-62, 2017. 
[42] M. F. F. Wong, "Factors associated with anxiety and depression among patients with implantable cardioverter defibrillator", JOCN, 26 (9-10), 1328-1337, 2017. DOI: 10.1111/jocn.13637.

[43] D. O. Clark, T. E. Stumpp, W. Tu, and D. K. Miller, "A Comparison and cross-validation of models to predict basic activity of daily living dependency in older adults", Med Care, 50, 534-539, 2012.

[44] R. D. Gallagher, S. McKinley, B. Mangan, D. Pelletier, J. Squire, and S. Mitten-Lewis, "The impact of the implantable cardioverter defibrillator on quality of life", Am J Crit Care, 6 (1), 16-24, 1997.

[45] D. Pelletier, R. Gallagher, S. Mitten-Lewis, S. McKinley, \& Squire J., "Australian implantable cardiac defibrillator recipients: Quality-of-life issues", Int J Nurs Pract, 8(2), 68-74, 2002.

[46] R. L. Walker, K. A. Campbell, S. F. Sears, B. A. Glenn, R. Sotile, A. B. Curtis, and J. B. Conti, "Women and the implantable cardioverter defibrillator: A lifespan perspective on key psychosocial issues", Clin Cardiol, 27(10), 543-546, 2004.

[47] R. L. Wallace, S. F. Sears, T. S. Lewis, J. T. Griffis, A. Curtis, and J. B. Conti, "Predictors of quality of life in long-term recipients of implantable cardioverter defibrillators", J Cardiopulm Rehabil, 22(4), 278-281, 2002.

[48] M. Gott, S. Barnes, C. Parker, S. Payne, D. Seamark, S. Gariballa, and N. Small, "Predictors of the quality of life of older people with heart failure recruited from primary care", Age Ageing, 35, 172-177, 2006.

[49] S. S. Gottlieb, M. Knatta, E. Friedmann, L. Einbinder, S. Katzen, B. Baker, J. Marshall, et al., "The influence of age, gender, and race on the prevalence of depression in heart failure patients", J Am Coll Cardiol, 43, 1542-1549, 2004.
[50] S. F. Sears, J. L. Burns, E. Handberg, W. M. Sotile, and J. B. Conti, "Young at heart: understanding the unique psychosocial adjustment of young implantable cardioverter defibrillator recipients", PACE, 24, 11131117, 2001.

[51] E. B. Schron, D. V. Exner, Q. Yao, L. S. Jenkins, J. S. Steinberg, J. R. Cook, S. P. Kutalek, et al., "Quality of life in the antiarrhythmics versus implantable defibrillators trial: impact of therapy and influence of adverse symptoms and defibrillator shocks", Circulation, 105(5), 589-94, 2002.

[52] S. B. Dunbar, C. C. Dougherty, S. F. Sears, D. L. Carroll, N. E. Goldstein, D. B. Mark, G. McDaniel, S. J. Pressler, E. Schron, P. Wang, \& V. L. Zeigler, "Educational and psychological interventions to improve outcomes for recipients of implantable cardioverter defibrillators and their families", Circulation, 126, 2146-2172, 2012.

[53] A. C. C. O. Maia, A. A. Braga, G. Soares-Filho, V. Pereira, A. E. Nardi, and A.C. Silva, "Efficacy of cognitive behavioral therapy in reducing psychiatric symptoms in patients with implantable cardioverter defibrillator: An integrative review", Braz J Med Biol Res, 47(4), 265-272, 2014.

[54] M. Gilkson and P. A. Friedman, "The implantable cardioverter defibrillator', Lancet, 357, 1107-1117, 2001.

[55] M. H. van Beek, R. C. Oude Voshaar, A. M. Beek, G. A. van Zijderveld, S. Visser, A. E. Speckens, A.E. Speckens, et al., "A brief cognitive-behavioral intervention for treating depression and panic disorder in patients with noncardiac chest pain: a 24-week randomized controlled trial”, Depress Anxiety, 30(7), 670-678, 2013. 